Journal of Applied Pharmaceutical Science Vol. 5 (06), pp. 088-096, June, 2015

Available online at http://www.japsonline.com

DOI: $10.7324 /$ JAPS.2015.50615

ISSN 2231-3354 (cc) BY-NC-SA

\title{
Formulation and characterization of ternary complex of poorly soluble duloxetinehydrochloride
}

\author{
Pinakin Pandya, Narendra Kumar Pandey*, Sachin Kumar Singh, Manish Kumar \\ School of Pharmaceutical Sciences, Lovely Professional University, Punjab - 144411, India.
}

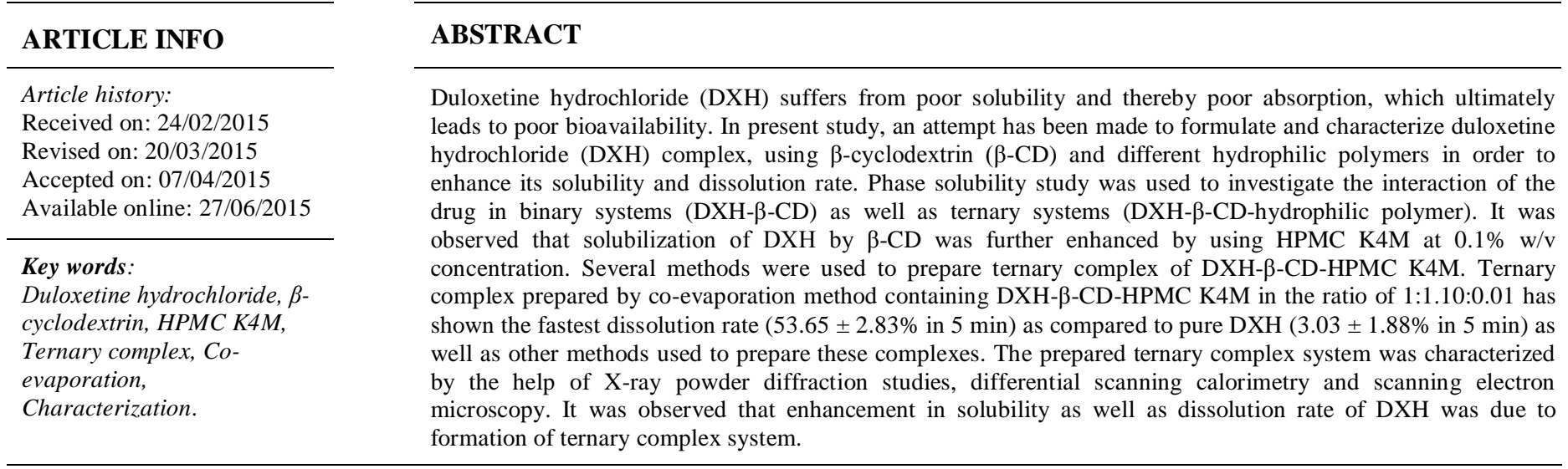

\section{INTRODUCTION}

Duloxetine hydrochloride (DXH) is used for the treatment of major depressive disorder (MDD). It is relatively balanced and potent inhibitor of both 5-Hydroxy Tryptamine (5HT) and Nor-epinephrine (NE) reuptake, with weak effects on dopamine reuptake (Tran et al., 2003). DXH belongs to BCS class-II and thus has poor aqueous solubility. Due to its poor aqueous solubility, after oral administration it possesses lower solubility in the GI fluids. This causes its excretion from the GI tract before its complete dissolution and absorption into the systemic circulation. This causes lower absorption, decreased bioavailability (BA) and poor dose proportionality, which ultimately leads to sub-optimal dosing and poor drug performance (Elkordy et al., 2013). Hence, there is a need to formulate DXH using suitable technique that could be able to enhance its poor aqueous solubility and thereby dissolution rate. The techniques like, particle size reduction to micron or, submicron level (Kubo, 1996; Singh et al., 2011), amorphization

* Corresponding Author

Email: herenarendra4u@gmail.com
(Latinen et al., 2012; Chieng et al., 2008), co-amorphization (Alleso et al., 2009), formulation of inclusion complexes (Ruan et al., 2005; Singh et al., 2012), solid dispersions (Singh et al., 2011; Barzegar-Jalali and Dastmalchi, 2007; Corrigan, 1985), generation of metastable polymorphs (Renuka et al., 2014), lipid based systems (Pouton, 2000) like self - emulsifying drug delivery systems (SEDDS) have succeeded to deliver poorly soluble drugs with enhanced dissolution profile. Complexation of the API with the complexing agents like $\beta$-cyclodextrin is one of the most promising techniques used to enhance the dissolution rate of poorly water soluble drugs. Cyclodextrins have received increasing interest in the pharmaceutical field because of their ability to modify physical, chemical and biological properties of a number of hydrophobic drug molecules through the formation of inclusion complexes (Szejli, 1998; Uekama et al., 1998). However, due to various reasons (such as their high molecular weight, relatively low water solubility and possible parenteral toxicity) the amount of cyclodextrins that can be used in most pharmaceutical formulations is limited (Loftsson and Brewster, 1996). Among the different approaches undertaken with this aim, recent works showed that the addition of suitable auxiliary substances can significantly increase the cyclodextrin solubilizing and complexing abilities by 
multicomponent complex formation (Loftsson and Brewster, 1996). For instance, it was shown that the addition of small amounts of a suitable water-soluble polymer to a drugcyclodextrin system can improve the performance of the cyclodextrin (Loftsson et al., 1994; Ganzerli et al., 1996; Loftsson et al., 1996). On the other hand, the influence of hydroxy acids in intensifying the cyclodextrin-solubilizing power toward basic drugs can be seen as a result of the combined effects of salt formation and inclusion complexation (Redenti et al., 2000; Mura et al., 2001). Ternary complexation involving salt formation was also reported for acidic drugs (Redenti et al., 2001; Vikmon et al., 1999; Piel et al., 1997). In the present study, an attempt has been made to formulate different complexes of DXH using $\beta$ cyclodextrin $(\beta-C D)$ as complexing agent. The effect of complexation of DXH on its solubility and dissolution rate has been studied. Furthermore, the influence of different hydrophilic polymers in form of ternary complex (i.e. DXH: $\beta$-CD: Polymer) on solubility and dissolution rate of $\mathrm{DXH}$, has also been studied.

\section{MATERIALS AND METHODS}

\section{Materials}

Duloxetine Hydrochloride (DXH) was kindly provided by Intas Pharma., Gujarat, India. HPMC K4M and HPMC E5LV were procured from Colorcon Asia Ltd., Goa, India. $\beta$ cyclodextrin $(\beta-C D)$ was purchased from Central Drug House, New Delhi, India. PVP K-25, PVP K-30, cross caremellose sodium were provided by Loba Chemie Ltd., Mumbai, India.

\section{Solubility studies of DXH using cyclodextrin and different polymers \\ Phase solubility studies}

Phase solubility studies were carried out according to Higuchi and Connors method (Higuchi and Connors, 1965). An excess amount of DXH was added to $10 \mathrm{ml}$ of phosphate buffer $(\mathrm{pH}$ 6.8) containing various concentrations of $\beta-\mathrm{CD}(0-10 \mathrm{mM})$ in $10 \mathrm{ml}$ volumetric flasks. Dispersions were shaken for $24 \mathrm{~h}$ at room temperature $\left(25 \pm 2^{\circ} \mathrm{C}\right)$ on a mechanical shaker at $150 \mathrm{rpm}$. Further, suitable aliquots were withdrawn and filtered through nylon filter paper $0.45 \mu \mathrm{m}$ (Nylon Acrodisc, Gelman, USA). The filtered solutions were analysed UV-Spectrophotometrically (UV 1800, Shimadzu, Japan) at $289 \mathrm{~nm}$. The apparent solubility constant $\left(\mathrm{K}_{\mathrm{S}}\right)$ and complexation efficiency $(\mathrm{CE})$ were calculated as follow:

$$
\mathrm{K}_{\mathrm{S}}=\text { Slope } / \mathrm{S}_{\mathrm{o}}(1-\text { Slope })
$$

Complexation efficiency $(\mathrm{CE})=$ Slope $/(1-$ Slope $)$

Where, $S_{o}$ is the solubility of drug in absence of $\beta-C D$

\section{Effect of preheating and type of polymer on complexation efficacy of cyclodextrin}

In this study an attempt has been made to evaluate the influence of different type of polymers on the complexation efficiency of $\beta$-CD. In view of this, four $10 \mathrm{ml}$ standard volumetric flasks were taken, and $6 \mathrm{mM}$ of $\beta-\mathrm{CD}$ was transferred to each of the flasks. Further, to the first volumetric flask HPMC K4M, to second volumetric flask HPMC E5LV, to third volumetric flask PVP K-30 and to the fourth volumetric flask PVP K-25 were added in a concentration of $0.25 \% \mathrm{w} / \mathrm{v}$. To all these flasks a known excess of DXH was added and the solutions were kept on a mechanical shaker at $150 \mathrm{rpm}$ at $25 \pm 2{ }^{\circ} \mathrm{C}$ for $24 \mathrm{~h}$. Afterwards, suitable aliquots of samples were withdrawn, filtered through 0.45 $\mu \mathrm{m}$ membrane filter and analysed spectrophotometrically at 289 nm. Further, this study was explored to check combined effect of preheating and type of polymers on complexation efficiency of $\beta$ CD. In this the solutions containing DXH were prepared in the same way, but prior to subject the solutions for mechanical shaking for $24 \mathrm{~h}$, they were kept in hot air oven at $60-70^{\circ} \mathrm{C}$ for $1 \mathrm{~h}$. Further, the samples were kept on mechanical shaker and the study was carried out as described in the above paragraph.

\section{Optimization of suitable concentration of hydrophilic polymer}

In order to achieve the optimum concentration of selected polymer (i.e. HPMC K4M and PVP K-25), a series of solutions were prepared for both polymers, in the range of 0 to $0.4 \% \mathrm{w} / \mathrm{v}$. To all these solutions, $6 \mathrm{mM}$ of $\beta-\mathrm{CD}$ and a known excess of DXH were added. Samples were heated in hot air oven at $70^{\circ} \mathrm{C}$ for $1 \mathrm{~h}$ prior to put on mechanical shaker at $25 \pm 2{ }^{\circ} \mathrm{C}$ for $24 \mathrm{~h}$. After equilibration at room temperature, the suspension was filtered through $0.45 \mu \mathrm{m}$ nylon filter and analysed spectrophometrically at $289 \mathrm{~nm}$ after necessary dilution using $0.2 \mathrm{M}$ phosphate buffer $(\mathrm{pH}$ $6.8)$.

\section{Preparation of solid complex}

Solid complex for ternary complex system (DXH: $\beta-\mathrm{CD}$ : HPMC K4M = 1:1.10:0.01) was formulated by various methods such as physical mixing, kneading, co-precipitation and coevaporation method. Description of methods is discussed in following sections:

\section{Physical mixing}

Physical mixture was prepared by taking $\mathrm{DXH}, \beta-\mathrm{CD}$ and HPMC K4M in required ratio. The individual components were sieved (60\#) prior to mixing. Mixing was done for 30 and 60 min to investigate effect of mixing time on complexation. These powdered mixtures were stored in desiccator at $25 \pm 2{ }^{\circ} \mathrm{C}$.

\section{Kneading method}

For preparation of ternary complex, DXH, $\beta-\mathrm{CD}$ and HPMC K4M in required quantity, were wetted with minimum quantity of water in order to obtain pasty mass. To evaluate the effect of trituration time, kneading was carried out for 30 and 60 min, respectively. Afterwards, obtained powders were kept for drying at $50^{\circ} \mathrm{C}$ for one day, further they were crushed, sieved (60\#) and stored in desiccator at $25 \pm 2{ }^{\circ} \mathrm{C}$.

\section{Co-precipitation method}

HPMC K4M and $\beta-C D$ were dissolved in $50 \mathrm{ml}$ of water maintained at $75^{\circ} \mathrm{C}$ on a magnetic stirrer. DXH $(100 \mathrm{mg})$ was 
dissolved in $10 \mathrm{ml}$ of methanol. This was added drop wise into the aqueous solution of HPMC K4M and $\beta$-CD. Stirring was continued up to $1 \mathrm{~h}$ at $75^{\circ} \mathrm{C}$. The solution was gradually cooled to room temperature. The obtained precipitates were filtered, dried, sieved (60\#) and stored in desiccator at $25 \pm 2{ }^{\circ} \mathrm{C}$.

\section{Co-evaporation method}

Known amount of DXH, $\beta-\mathrm{CD}$ and HPMC K4M were added in $50 \mathrm{ml}$ of $50 \%$ aqueous ethanol to obtain suspension. The suspension was kept for sonication to get clear solution. This solution was subjected to evaporate on magnetic stirrer at $70^{\circ} \mathrm{C}$. The obtained complex was dried, sieved (60\#) and stored in desiccator at $25 \pm 2{ }^{\circ} \mathrm{C}$.

\section{In vitro dissolution study}

Powders containing DXH equivalent to $22 \mathrm{mg}$ were taken from each batch of prepared complexes and filled into transparent capsule shell. The capsules were subjected for in vitro dissolution study. Dissolution study was performed by using USP I (basket type) dissolution test apparatus (DS 8000, Lab India, Mumbai, India).

Experiment was conducted in $900 \mathrm{ml}$ dissolution medium (0.2 $\mathrm{M}$ phosphate buffer $\mathrm{pH} 6.8)$ using $75 \mathrm{rpm}$ at $37 \pm 0.5^{\circ} \mathrm{C}$. Samples $(5 \mathrm{ml})$ were withdrawn at predetermined time intervals from the dissolution medium and equal volume was replaced immediately by fresh medium. The withdrawn samples were filtered through $0.45 \mu \mathrm{m}$ membrane filter and analysed spectrophotometricaly at $289 \mathrm{~nm}$.

\section{Characterization of complex and physical mixture}

The thermal behavior of different components (DXH, $\beta$ CD, HPMCK4M), physical mixture as well as formulated complex powder (selected batch) were investigated using a differential scanning calorimeter (DSC). Sample (2.5 mg) was heated in hermetically sealed standard aluminum pan. The thermograms were obtained over the temperature range of $50-250^{\circ} \mathrm{C}$ with heating rate of $10^{\circ} \mathrm{C} / \mathrm{min}$ under nitrogen atmosphere maintained at flow rate of $50 \mathrm{ml} / \mathrm{min}$.

The X-ray powder diffraction (XRPD) studies were carried out to determine crystallinity of drug in the complex and physical mixture. XRPD pattern of individual components (DXH, $\beta-\mathrm{CD}, \mathrm{HPMC} \mathrm{K} 4 \mathrm{M}$ ), physical mixtures and inclusion complex were recorded on scanning powder X-ray diffractometer using an X'Pert PRO instrument, equipped with an X'Pert PRO Data Collector software. The radiation used was generated by a $\mathrm{Cu} / \mathrm{K} \alpha$ source fitted with a Ni filter at $0.154 \mathrm{~nm}$ wavelengths at $40 \mathrm{~mA}$ and $45 \mathrm{kV}$. Samples were scanned for $2 \theta$ values over a range from $5-45^{\circ} \mathrm{C}$, at scan rate of $10^{\circ} \mathrm{C} / \mathrm{min}$.

The surface morphology of the $\mathrm{DXH}, \beta-\mathrm{CD}$, physical mixture and inclusion complex (selected batch) were examined by scanning electron microscopy (SEM). Samples were fixed on brass stub using double-sided tape and made electrically conductive by coating with a thin layer of gold by sputter coater (Ion sputter E1010). Photographs were taken at an electric voltage of $15 \mathrm{kV}$.

\section{RESULTS AND DISCUSSION}

\section{Solubility studies using cyclodextrin and different polymers Phase solubility studies}

According to Higuchi and Connors (1965), phase solubility diagram (Fig. 1) can be categorized as type Bs. Such phase solubility diagram is typically obtained while $\beta-C D$ is used as a complexing agent because of its low solubility $(1.8 \mathrm{~g} / 100 \mathrm{ml})$ (Martin Del Valle, 2004). Fig. 1 showed that at higher concentration of $\beta-\mathrm{CD}$, there was formation of insoluble complex that led to decrease in drug solubility. In order to find out the amount of drug that can fit into $\beta$-CD cavity, binding constant was determined by taking slope of initial inclined portion of phase solubility diagram. The slope of phase solubility diagram was found to be 0.2883 , which was less than 1 (Table 1). This indicated that 1:1 inclusion complex formation has been achieved. Binding constant (Ks) and complexation efficiency (CE) were found to be 151.15 and 0.4 (Table 1). Lower complexation efficiency (0.4) indicated that free $\beta$-CD was more available in aqueous media (Loftsson et al., 2005).

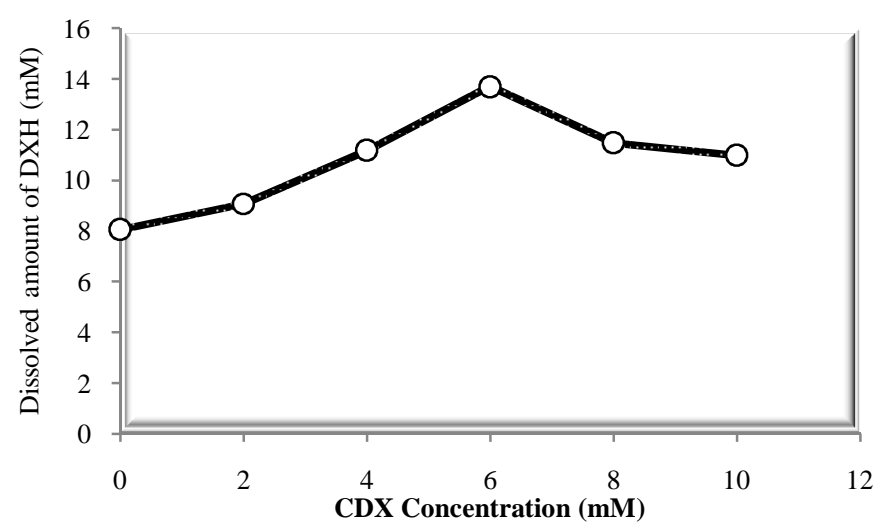

Fig. 1: Phase solubility diagram of DXH in $\beta-C D(0-10 \mathrm{mM})$.

\section{Effect of preheating and type of polymer on complexation efficacy of cyclodextrin}

Results obtained for DXH solubility in presence of polymer are shown in Fig. 2. Among all the polymers tested for complexation, the solubility of DXH was found to be higher in case of PVP K-25 and HPMC K4M (Fig. 2). Moreover, when this phenomenon was tested with the effect of preheating, it was observed that preheating of DXH- $\beta$-CD-polymer has increased the drug solubility as compared to non-heated solutions. This indicated that at elevated temperature, complexation efficiency of $\beta$-CD has increased (Loftsson and Sigurdardottir, 1996; Maragos et al., 2009). It has been reported in literature that addition of polymer to the complex further enhances the solubility of drug due to molecular interactions such as formation of hydrophobic bonds, Van der Waals dispersion forces, or hydrogen bond and/or promoting the release of high-energy water molecules present in their cavity (Rekharshy and Inoue, 1998; Fridriksdottir et al., 1994). An enhancement in drug solubility was observed with HPMC K4M ( $8.523 \mathrm{mg} / \mathrm{ml})$ and PVP K-25 (7.309 mg/ml) $\left(\mathrm{S}_{1}\right)$ which was about 3.180 and 2.727 fold more as compared to 
intrinsic solubility $\left(\mathrm{S}_{0}\right)$ of DXH (Table 2$)$. The ratio of solubility enhancement in between ternary system to binary system with cyclodextrin $\left(\mathrm{S}_{\mathrm{TS}} / \mathrm{S}_{\mathrm{BS}}{ }^{\mathrm{g}}\right)$ was also found to be greater in HPMC $\mathrm{K} 4 \mathrm{M}$ and PVP K-25 i.e. 1.804 and 1.547 as compared to those obtained in case of HPMC E5LV and PVP K-30. This might be due to effect of structure and polymer viscosity on weak hydrogen bonding interaction, which is normally observed in ternary complex system of polymer, cyclodextrin and drug molecule (Faucci and Mura, 2001; Ribeiro et al., 2003).

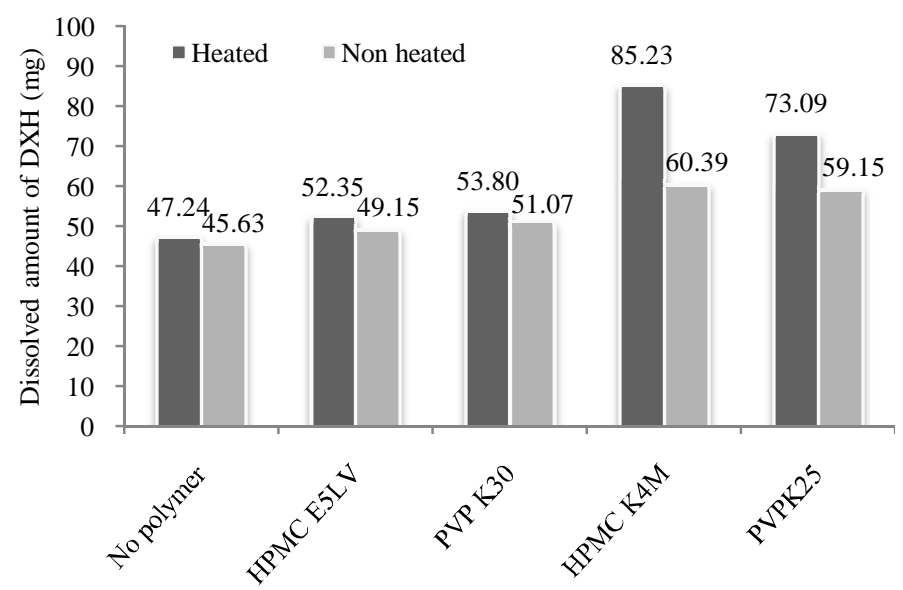

Fig. 2: Comparative evaluation of preheated and non-heated samples of ternary complex solution [i.e. $\beta-\mathrm{CD}(6 \mathrm{mM})$ and hydrophilic polymer $(0.25 \% \mathrm{w} / \mathrm{v})]$.

Ternary complex system (TS) was also found to be superior as compared to binary system (BS) prepared by using water soluble polymers (HPMC K4M and PVP K-25). It was computed by determining the solubility enhancement ratio $\left(\mathrm{S}_{\mathrm{TS}} /\right.$ $\mathrm{S}_{\mathrm{BS}}{ }^{\mathrm{h}}$ ) in between binary system (DXH - HPMC K4M and DXHPVP K-25) and ternary complex system (DXH- $\beta$-CD-HPMC K4M and DXH- $\beta$-CD -PVP K-25). The value was found to be 1.736 and 1.606 for HPMC K4M and PVP K-25, respectively (Table 2).

The ratio of pre-heated system and non-heated system $\left(\mathrm{S}_{\mathrm{HS}} / \mathrm{S}_{\mathrm{NHS}}\right)$ was found to be 1.411 and 1.236 for HPMC K4M and PVP K-25, which has further confirmed importance of preheating before samples were kept on equilibration. This ratio was lower in case of HPMC E5LV and PVP K-30, which might be due to the effect of viscosity of polymer.

\section{Optimization of suitable concentration of hydrophilic polymer}

Phase solubility diagram of DXH in ternary system (DXH- $\beta$-CD- HPMC K4M and DXH- $\beta$-CD- PVP K-25) in the range of $(0-0.3 \% \mathrm{w} / \mathrm{v})$ is represented in Fig.3. Complexation constant of DXH- $\beta$-CD- HPMC K4M and DXH- $\beta$-CD- PVP K25 was computed from the slopes of the corresponding regression lines obtained from initial straight line portion. The slope value was found to be less than 1 that reflected that there was formation of 1:1 complex (Table 3). It was observed that solubility of complex decreased at higher polymer concentrations. This could be due to formation of water-insoluble inclusion complexes between the polymer and $\beta-\mathrm{CD}$. Such precipitates are commonly formed when polyrotaxanes of $\beta-C D$ are formed in aqueous solutions (Fujita et al., 1996). Addition of polymer further enhanced the solubility constant, which could be attributed to the increase in cyclodextrin complexation efficiency towards DXH. The ratio of binding constant in ternary system and binary system $\left(\mathrm{K}_{\mathrm{TS}} / \mathrm{K}_{\mathrm{BS}}\right.$ ) was found higher in HPMC K4M than PVP K-25 (4.87 $>$ 2.07) (Table 3).

Moreover, the solubility ratio in ternary system and binary system $\left(\mathrm{S}_{\mathrm{TS}} / \mathrm{S}_{\mathrm{BS}}\right)$ was greater for HPMC K4M than PVP K$25(2.64>2.21)$. The results revealed that solubility enhancement effect of HPMC K4M was found higher as compared to PVP K25 . Hence, DXH: $\beta-C D: H P M C ~ K 4 M$ complex system was selected for preparation of solid complexes using physical mixing, kneading, co-precipitation and co-evaporation methods. Binary complex system (DXH: $\beta-\mathrm{CD})$ has been excluded for preparation of solid complex system.

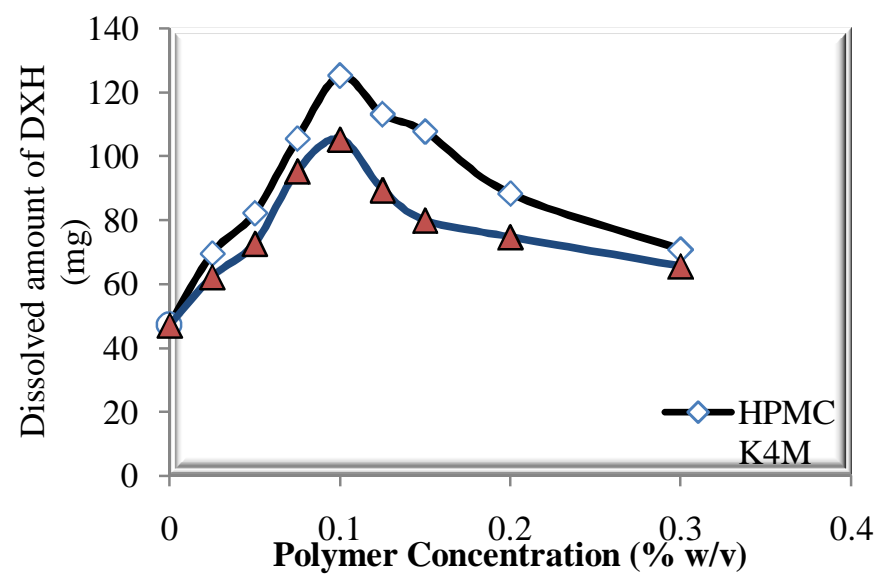

Fig. 3: Phase solubility diagram of DXH in ternary complex system [i.e. polymer in HPMC and PVP K-25 (0-0.3\% w/v) with constant $\beta-\mathrm{CD}(6 \mathrm{mM})]$.

\section{Evaluation of formulated complexes \\ In vitro dissolution study}

Mean dissolution profile for pure drug (DXH) and ternary complex system (DXH: $\beta-\mathrm{CD}$ : HPMCK4M) prepared by physical mixing (P.M.), kneading (K.M.), co-precipitation (Coppt.) and co-evaporation (Co-evap.) is shown in Table 4 and Fig.4. The release of pure DXH was 30 found to be only $75.68 \%$ in 30 min. However the release of pure DXH within 15 min was just $38.39 \%$. This is due to poor aqueous solubility of DXH and hence, this gave significance for formulation of complexation of DXH with $\beta-C D$ and other solubilizing agent. In case of ternary complex systems, a drastic difference in release of DXH was found as compared to pure drug. Among all the methods for preparation of complex, co-evaporation method was found to be best method in terms of DXH release. DXH release was found to be $53.65 \pm 2.83 \%$ in 5 min for DXH- $\beta$-CD-HPMC K4M complex prepared by co-evaporation method, which was 17 folds more than the pure API $(3.03 \pm 1.88 \%)$. More than $85 \%$ of drug got released in $15 \mathrm{~min}$ for inclusion complex powder prepared by coevaporation method, whereas release of pure drug was found to be only $75 \%$ in $30 \mathrm{~min}$. 
Table 1: Analytical parameter of phase solubility diagram and estimated value of binding constant (Ks) and complexation efficiency (CE).

\begin{tabular}{lcccc}
\hline Parameter & S0* & Slope & Regression coefficient (r2) & Value \\
\hline $\begin{array}{l}\text { Binding Constant }(\mathrm{Ks}) \\
\text { Complexation efficiency (CE) }\end{array}$ & 0.00268 & 0.2883 & 0.9882 & 151.15 \\
\hline
\end{tabular}

*indicates solubility in $\mathrm{g} / \mathrm{ml}$

Table 2: Evaluation of intrinsic solubility of drug $\left(\mathrm{S}_{0}\right)$ and solubility enhancement factor.

\begin{tabular}{|c|c|c|c|c|c|c|c|}
\hline \multirow[t]{2}{*}{ Component } & \multirow[t]{2}{*}{ Treatment } & \multicolumn{6}{|c|}{ Solubility of Drug $(n=3)$} \\
\hline & & $\mathbf{S}_{0}{ }^{\mathrm{d}}$ & $\mathrm{S}_{1}{ }^{\mathrm{e}}$ & $S_{1} / S_{0}{ }^{f}$ & $\mathbf{S}_{\mathrm{TS}} / \mathbf{S}_{\mathrm{BS}}{ }^{\mathrm{g}}$ & $\mathbf{S}_{\mathrm{TS}} / \mathbf{S}_{\mathrm{BS}}{ }^{\mathrm{h}}$ & $\mathbf{S}_{\mathrm{HS}} / \mathbf{S}_{\mathrm{NHS}}{ }^{\mathrm{i}}$ \\
\hline Drug & & 2.68 & & & & & \\
\hline \multicolumn{8}{|c|}{ Binary complex system } \\
\hline$\beta-C D^{a}$ & \multirow{3}{*}{ Preheated } & & 4.724 & 1.763 & & & 1.044 \\
\hline HPMC K4M ${ }^{\mathrm{b}}$ & & & 4.910 & 1.832 & & & \\
\hline PVP K-25 & & & 4.550 & 1.698 & & & \\
\hline$\beta-\mathrm{CD}^{\mathrm{a}}$ & Non- heated & & 4.524 & 1.688 & & & \\
\hline \multicolumn{8}{|c|}{ Ternary complex system ${ }^{\mathrm{C}}$} \\
\hline HPMC E5LV & \multirow{4}{*}{ Preheated } & & 5.235 & 1.953 & 1.108 & & 1.065 \\
\hline HPMC K4M & & & 8.523 & 3.180 & 1.804 & 1.736 & 1.411 \\
\hline PVP K-25 & & & 7.309 & 2.727 & 1.547 & 1.606 & 1.236 \\
\hline PVP K-30 & & & 5.380 & 2.007 & 1.139 & & 1.053 \\
\hline HPMC E5LV & \multirow{4}{*}{ Non- heated } & & 4.915 & 1.834 & 1.040 & \multirow{4}{*}{$\begin{array}{l}1.230 \\
1.300\end{array}$} & \\
\hline HPMC K4M & & & 6.039 & 2.253 & 1.278 & & \\
\hline PVP K-25 & & & 5.915 & 2.207 & 1.252 & & \\
\hline PVP K-30 & & & 5.107 & 1.906 & 1.081 & & \\
\hline \multicolumn{8}{|c|}{ 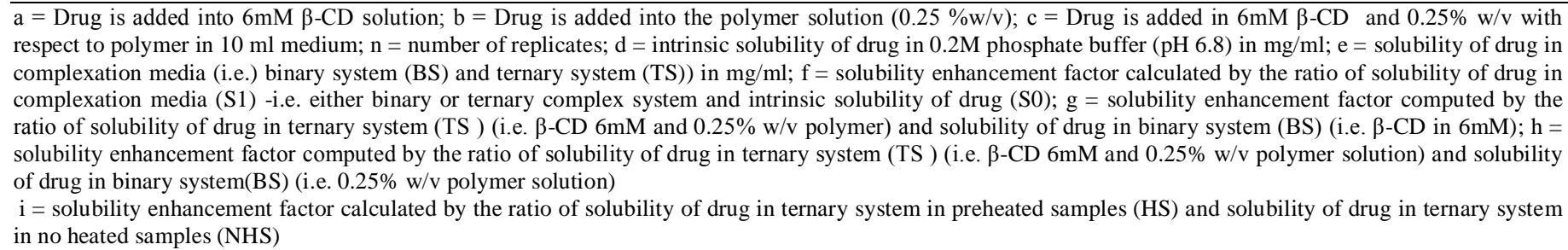 } \\
\hline
\end{tabular}

Table 3: Analytical parameter evaluation in ternary complex system and determination of solubility enhancement factor.

\begin{tabular}{|c|c|c|c|c|c|}
\hline Complexation media & Slope & Regression co-efficient (r) & Ks & STS/SBS c & KTS/KBS d \\
\hline$\beta-\mathrm{CD}$ a & 0.2883 & 0.9882 & 151.15 & & \\
\hline HPMC K4Mb & 0.7693 & 0.9938 & 736.72 & 2.64 & 4.87 \\
\hline PVP K-25b & 0.5974 & 0.9862 & 314.11 & 2.21 & 2.07 \\
\hline
\end{tabular}

$\mathrm{a}=6 \mathrm{mM} \beta$-CD solution; $\mathrm{b}=$ ternary complexation medium consisted of $6 \mathrm{mM} \beta$-CD and $0.1 \% \mathrm{w} / \mathrm{v}$ hydrophilic polymers. $\mathrm{c}=$ is the solubility ratio in between ternary system (TS) and binary system (BS); $\mathrm{d}=\mathrm{Kc}$ is the ratio of binding constant in between ternary system and binary system.

Table 4: Mean dissolution profile of pure drug (DXH) and its ternary complex system (DXH: $\beta$-CD:HPMC K4M) prepared by various methods.

\begin{tabular}{lcccccr}
\hline Time (min) & \multicolumn{7}{c}{ Mean cumulative drug release \pm S.D. $(\%)(\mathbf{m}=\mathbf{3})$} \\
& D & P.M. a & P.M. b & K.M. c & K.M. & C.P. \\
\hline 5 & $3.02 \pm 1.88$ & $6.71 \pm 2.38$ & $10.08 \pm 3.07$ & $15.76 \pm 5.49$ & $17.76 \pm 6.56$ & $30.87 \pm 2.48$ \\
10 & $15.52 \pm 3.67$ & $20.20 \pm 4.63$ & $23.28 \pm 2.79$ & $34.62 \pm 4.62$ & $31.07 \pm 7.17$ & $48.49 \pm 3.46$ \\
15 & $38.39 \pm 4.20$ & $47.51 \pm 6.63$ & $51.58 \pm 6.40$ & $62.47 \pm 5.32$ & $66.82 \pm 7.74$ & $73.00 \pm 2.85$ \\
20 & $55.27 \pm 6.67$ & $70.92 \pm 2.89$ & $77.03 \pm 5.79$ & $84.29 \pm 6.08$ & $89.51 \pm 2.43$ & $87.82 \pm 7.84$ \\
30 & $75.68 \pm 3.48$ & $86.84 \pm 5.41$ & $89.55 \pm 8.08$ & $90.40 \pm 4.26$ & $93.91 \pm 4.33$ & $92.49 \pm 7.06$ \\
\hline
\end{tabular}

$\mathrm{D}=$ Duloxetine hydrochloride; $\mathrm{a}=$ Physical mixing for $30 \mathrm{~min}$; $\mathrm{b}=$ physical mixing for $60 \mathrm{~min} ; \mathrm{c}=$ kneading of materials for 30 min; $\mathrm{d}=\mathrm{kneading}$ of materials for $60 \mathrm{~min}$; C.P. = complex prepared by co-precipitation method; C.E. = complex prepared by co-evaporation method.

\section{Characterization of complex and physical mixture}

The optimized ternary complex powder prepared by coevaporation method was characterized by DSC, XRD and SEM analysis.

\section{Differential scanning calorimetry studies}

DSC can be used for the recognition of inclusion complexes. When guest molecules were enclosed in cyclodextrin cavities or in the crystal lattices, their melting, boiling, or sublimation point generally shifted to a different temperature or disappeared (Cabral et al., 1990). The thermogram of DXH, $\beta-\mathrm{CD}$, ternary physical mixture and ternary inclusion complex prepared by co-evaporation method are presented in Fig. 5. The DSC thermogram of DXH (Fig. 5-A) exhibited a sharp crystalline endothermic peak at $169^{\circ} \mathrm{C}$, indicating the melting point of $\mathrm{DXH}$. The thermogram of $\beta$-CD (Fig. 5-B) showed a very broad endothermic peak in between 60 and $110^{\circ} \mathrm{C}$, which corresponded to dehydration process followed by solid-solid phase transition at $214^{\circ} \mathrm{C}$ (Giordano et al., 2001; Liu and Zhu, 2006). Thermogram of HPMC K4M revealed its amorphous behavior as it has no any endothermic peak (Fig. 5-C). For ternary physical mixture of $\beta$ CD: DXH : HPMC K4M (Fig. 5-D), the drug endothermic peak was slightly shifted from $169.05^{\circ} \mathrm{C}$ to $165.67^{\circ} \mathrm{C}$, but the height of the peak was not much affected. However, the enthalpy of fusion 
required to melt DXH physical mixture was decreased $(33.24 \mathrm{~J} / \mathrm{g}$ ) as compared to that of pure DXH $(79.64 \mathrm{~J} / \mathrm{g})$. It showed that there was an interaction between $\beta-\mathrm{CD}$, DXH and HPMC K4M. Whereas, in case of ternary complex prepared by co-evaporation method, peak was shifted to lower temperature $\left(169.05^{\circ} \mathrm{C}\right.$ to $158.56^{\circ} \mathrm{C}$ ) with significant reduction of height of peak (Fig. 5-E). The DSC thermogram showed that the energy required for melting of $\beta$-CD: DXH: HPMC K4M complex was lesser around (3.6 fold) than the energy required for pure DXH. This revealed that DXH
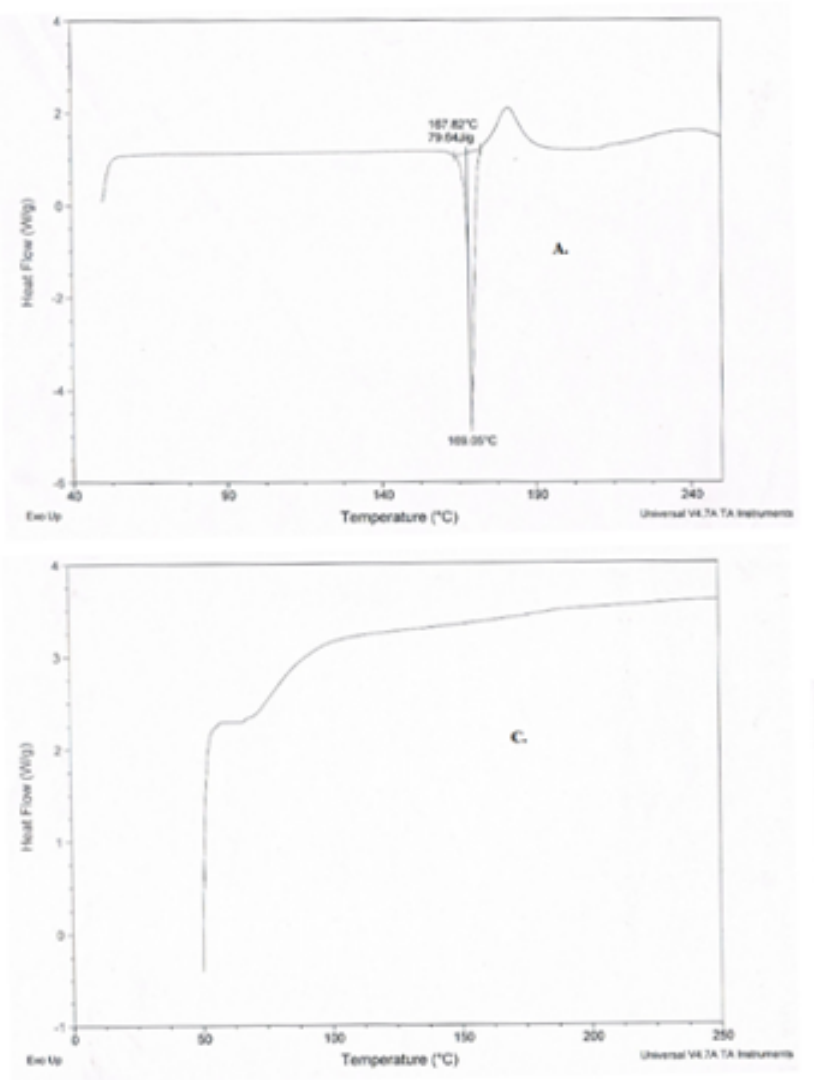

was completely included in the cavity of $\beta-C D$ which confirmed the observations obtained from complexation efficiency and binding constant studies. The amorphous HPMC K4M provided a larger surface area to the dissolution medium which allowed the dissolution medium to completely wet the DXH. This might be the reason behind the enhanced solubility and dissolution of DXH: $\beta$ CD: HPMC K4M complex. The observations of DSC were further confirmed by PXRD studies which are discussed in the subsequent section.

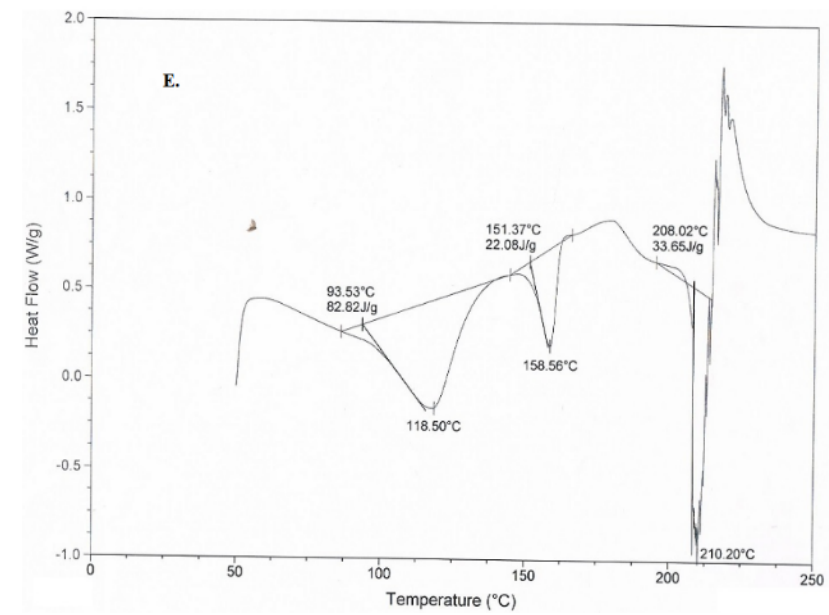

Fig. 5: DSC thermograms of DXH (A); $\beta$-cyclodextrin (B); HPMC K4M (C); ternary physical mixture (D) and inclusion complex powder prepared by co-evaporation method $(\mathrm{E})$. 

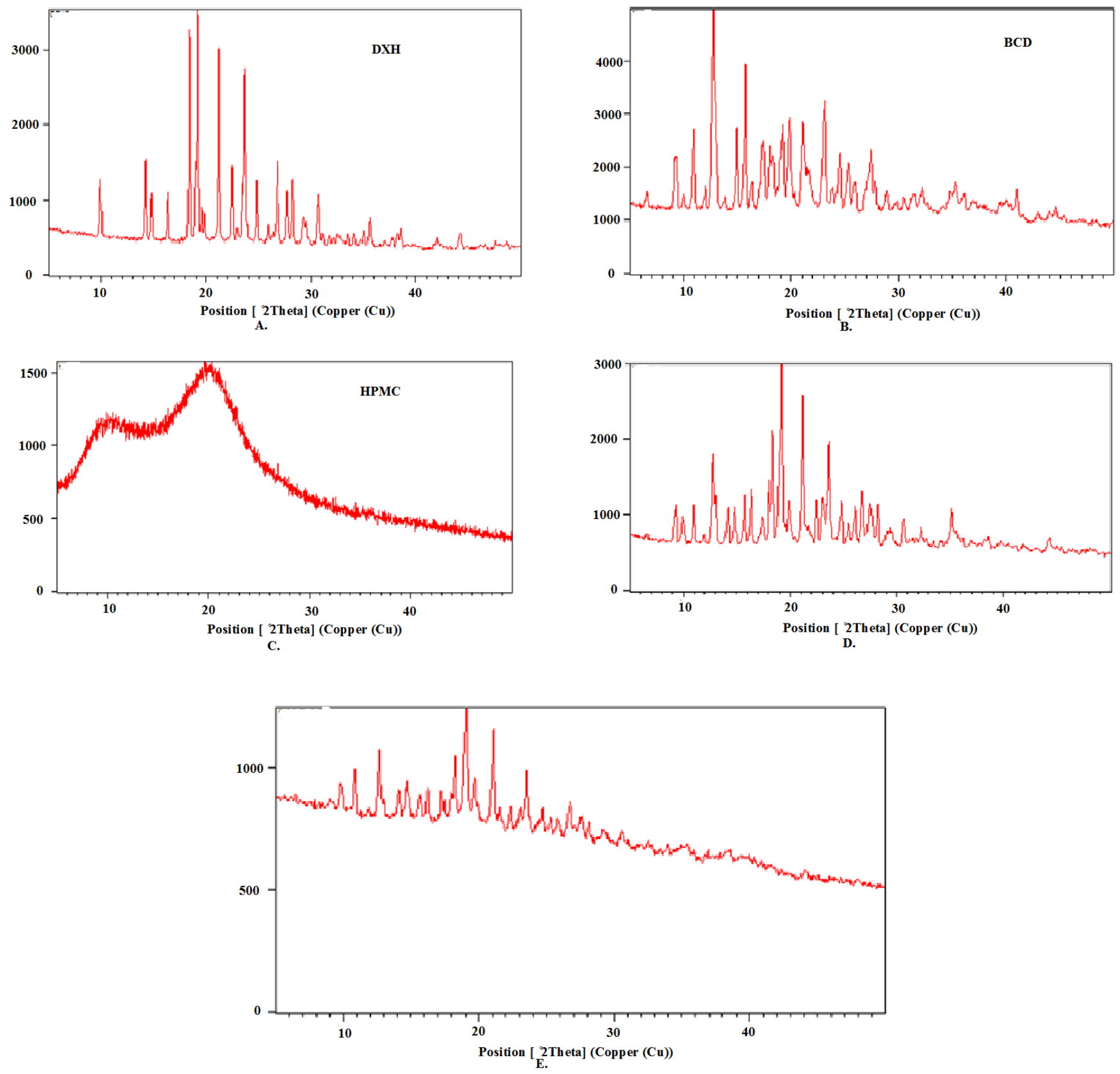

Fig. 6: PXRD spectra of DXH (A); $\beta$-CD (B); HPMC K4M (C); ternary physical mixture (D) and ternary inclusion complex prepared by co-evaporation method (E).
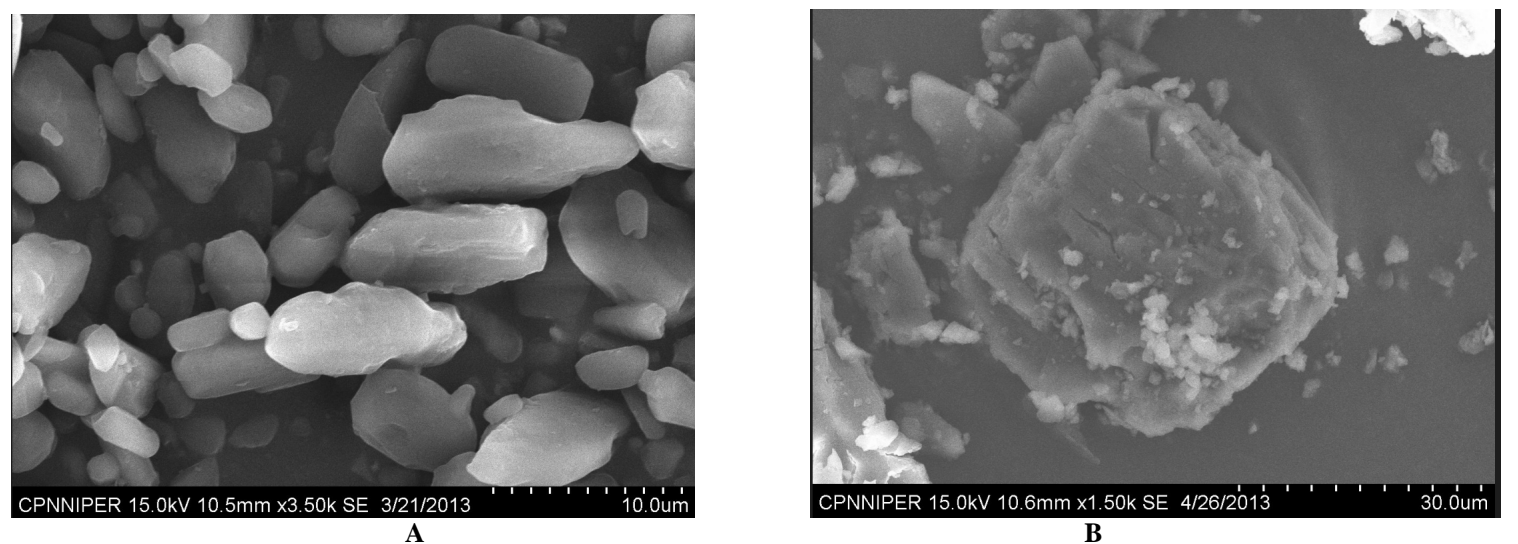

Fig. 7:... 


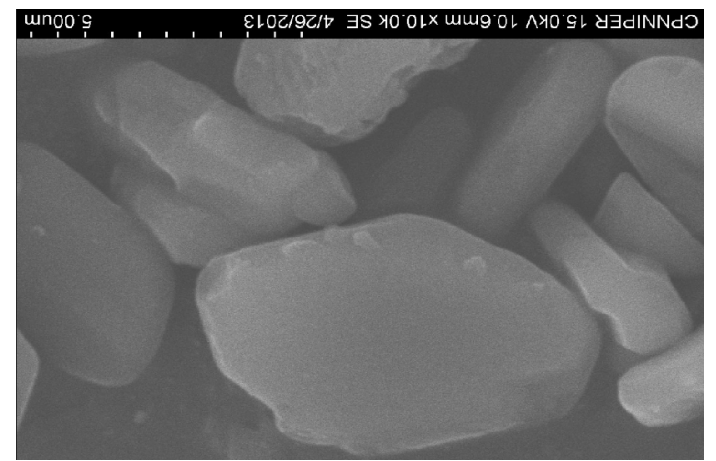

C

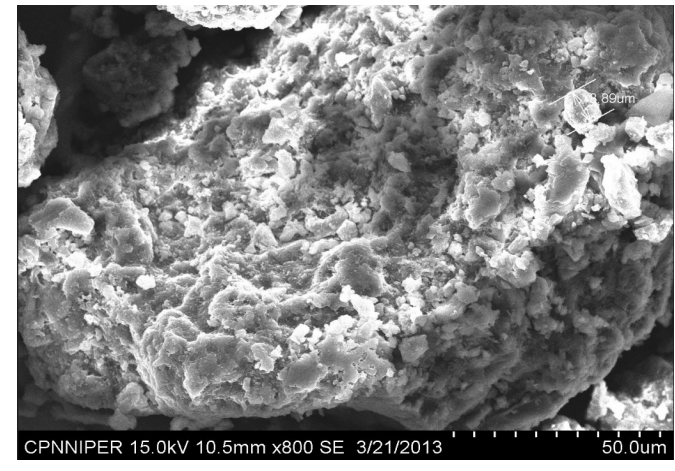

D

Fig.7: SEM of DXH (A); $\beta$-CD (B); ternary physical mixture (C) and ternary inclusion complex prepared by co-evaporation method (D).

\section{Powder X-Ray Diffraction studies}

The powder diffraction patterns of DXH, $\beta$-CD, HPMC $\mathrm{K} 4 \mathrm{M}$, ternary physical mixture (DXH: $\beta$-CD: HPMC K4M) and ternary inclusion complex (DXH: $\beta$-CD: HPMC K4M) prepared by co-evaporation method are shown in (Fig. 6). The PXRD pattern of drug (Fig. 6-A) was characterised by presence of sharp peaks at $14.21^{\circ}, 14.79^{\circ}, 18.37^{\circ}, 19.18^{\circ}, 21.17^{\circ}, 23.54^{\circ}$ indicative its crystalline behaviour. The crystalline nature of $\beta$-CD (Fig. 6-B) was evidenced from presence of sharp peaks at $7.31^{\circ}, 10.38^{\circ}$, $12.38^{\circ}, 14.48^{\circ}$ and 22.38 . The hallo pattern X-ray diffractograms obtained from HPMC K4M (Fig. 6-C) confirmed that it is amorphous in nature. The ternary physical mixture was characterized by presence of combined peaks of drug as well as $\beta$ $\mathrm{CD}$, however, with slightly reduced intensities (Fig. 6-D). In case of ternary complex prepared by co-evaporation method, the sharpness of peaks was found to decrease indicating loss of its crystalline behavior (Fig. 6-E). The sharpness as well as the number of sharp peaks existing with plain drug was found to be significantly diminished in case of ternary complex (DXH: $\beta$-CD: HPMC K4M). Lower intensities of the diffraction peaks were observed for the ternary complex of DXH: $\beta-\mathrm{CD}$ : HPMC K4M due to particle size reduction during mixing (Riberio et al., 2003). According to Williams et al., (1998), decrease of crystallinity is an added evidence for the formation of inclusion complex.

\section{Scanning electron microscopy (SEM) studies}

From SEM scans as seen in Fig. 7-A, pure DXH particle appeared as crystalline, $\beta$-CD particles (Fig. 7-B) appeared like cluster structure. Microscopic examination of ternary physical mixture (DXH: $\beta$-CD: HPMC K4M) (Fig. 7-C) showed the presence of DXH crystals mixed and adhered on the surface of CD particle revealing no apparent interaction between both species in the solid state. Ternary complex prepared by co-evaporation method, as seen in (Fig. 7-D) showed small and irregular piece and like engulfment of material in cavity. Fernandes et al., (2002), have reported that a modification in the shape of drug particles was indicative of a new solid state. Thus, change in the morphology of complex as compared to drug showed interaction between DXH and complexing agent. The result revealed that there might be increase the surface area of DXH due to complexation. Due to increased surface area, porosity of material was also increased. The improvement of porosity of material had further enhanced the wettability of material. The wettability (water uptake capacity) might have accelerated the solubility as well as dissolution rate of DXH.

\section{CONCLUSION}

The present study revealed that the solubility of DXH was found to be higher in ternary complex system (DXH: $\beta$-CD: HPMC K4M) as compared to binary complex systems (DXH: $\beta$ CD and DXH: HPMC K4M) and other ternary complex systems prepared by PVP K-25, HPMC E5LV and PVP K-30. Physical characterization techniques showed that crystallinity behaviour of DXH was found to be decreased due to formation of ternary complex system. This led to enhancement in solubility as well as dissolution rate of DXH. Ternary complex system was also found to give faster drug release as compared to pure API.

\section{ACKNOWLEDGEMENT}

We are highly obliged to Intas Pharma., Gujarat, India for providing gift samples of DXH. We also thank Dr. Monica Gulati, Senior Dean, School of applied medical sciences, Lovely Professional University, Punjab for her needful support.

\section{Conflict of interest}

The authors report no declaration of interest.

\section{REFERENCES}

Alles $\emptyset$ M, Chieng N, Rehder S, Rantanen J, Rades T, Aaltonen $\mathrm{J}$, Enhanced dissolution rate and synchronized release of drugs in binary systems through formulation: amorphous naproxen-cimetidine mixtures prepared by mechanical activation, J Control Rel, 2009; 136: 45-53.

Barzegar-Jalali M, Dastmalchi S, Kinetic analysis of chlorpropamide dissolution from solid dispersions, Drug Dev Ind Pharm, 2007; 33: 63-70.

Cabral MHM, Hadgraft J, Kellaway IW, Studies of cyclodextrin inclusion complexes-The salbutamol-cyclodextrin complex as studied by phase solubility and DSC, Int J Pharm, 1990; 63: 259-266.

Chieng N, Rades T, Saville D, Formation and physical stability of the amorphous phase of ranitidine hydrochloride polymorphs prepared by cryomilling, Eur J Pharm Biopharm, 2008; 68: 771-780. 
Corrigan OI, Mechanisms of dissolution of fast release solid dispersions, Drug Dev Ind Pharm, 1985; 11: 697-724.

Elkordy AA, Tan XN, Essa EA, Spironolactone release from liquisolid formulations prepared with Capryol ${ }^{\mathrm{TM}}$ 90, Solutol ${ }^{\circledR} \mathrm{HS}-15$ and Kollicoat ${ }^{\circledR}$ SR 30 D as non-volatile liquid vehicles, Eur J Pharm Biopharm, 2013; 83:203-223.

Faucci MT, Mura P, Effect of water-soluble polymer on naproxen complexation with natural and chemically modified $\beta$ cyclodextrin, Drug Dev Ind Pharm, 2001; 27: 909-917.

Fernandes CM, Vieira MT, Veiga FJB, Physicochemical characterization and in vitro dissolution behaviour of nicardipine $\beta$ cyclodextrins inclusion compounds, Eur J Pharm Sci, 2002; 15: 79-88.

Fridriksdottir H, Siiguroardottir AM, Ueda H, The effect of water soluble polymers on drug- cyclodextrin complexation, Int J Pharm, 1994; 110: $169-177$.

Fujita H, Ooya T, Kurisawa M, Hideharu M, Minoru T, Nobuhiko Y, Thermally switchable polyrotaxane as a model of stimuliresponsive supramolecules for nano-scale devices, Macromol Rapid Commun, 1996; 17: 509 - 515

Ganzerli G, Van SL, Verschuren E, Ludwig A, Influence of $\beta$ cyclodextrin and various polysaccharides on the solubility of fluorescein and on the rheological and mucoadhesive properties of ophthalmic solutions. Pharmazie, 1996; 51: 357-362.

Giordano F, Novak C, Moyano JR, Thermal analysis of cyclodextrins and their inclusion compounds, Thermochim Acta, 2001; 380: $123-151$.

Higuchi T, Connors KA, Phase-solubility techniques. Adv Anal Chem Instr, 1965; 4: 117-122.

Kubo H, Osawa T, Takashima K, Mizobe M, Enhancement of oral bioavailability and pharmacological effect of 1-(3,4dimethoxyphenyl)-2,3-bis(methoxycarbonyl)-4-hydroxy-6,7,8-

trimethoxynaphthalene (TA-7552), a new hypocholesterolemic agent, by micronization in co-ground mixture with D-mannitol, Biol Pharmacol Bull, 1996; 19: 741-747.

Laitinen R, Löbmann K, Strachan CJ, Grohganz H, Rades T, Emerging trends in the stabilization of amorphous drugs, Int J Pharm, 2012; 453: 65-79.

Liu L, Zhu S, Preparation and characterization of inclusion complexes of prazosin hydrochloride with $\beta$-cyclodextrin and hydroxypropyl- $\beta$-cyclodextrin, J Pharm Biomed Anal, 2006; 40: 122-127.

Loftsson T, Fridriksdóttir H, A.M. Sigurdardóttir AM, Ueda H, The effect of water-soluble polymers on drug-cyclodextrin complexation. Int J Pharm, 1994; 110: 169-177.

Loftsson T, Brewster ME, Pharmaceutical applications of cyclodextrins. 1. Drug solubilization and stabilization, J Pharm Sci, 1996; 85: 1017-1025.

Loftsson T, Gudmundsdóttir K, Fridriksdóttir F, The influence of water-soluble polymers and $\mathrm{pH}$ on hydroxypropyl-cyclodextrin complexation of drugs, Drug Dev Ind Pharm, 1996; 22: 401-405.

Loftsson T, Sigurdardottir AM, Cyclodextrins as skin penetration enhancers. In: Szejtli J, Szente L, ed. Proceedings of the Eighth International Symposium on CDs, Kluwer Academic, Dordrecht, (1996) pp. $509-515$.

Loftsson T, Hreinsdottir D, Masson M, Evaluation of cyclodextrin solubilization of drugs. Int. J. Pharm. 2005; 302: 18-28.

Maragos S, Archontaki H, Macheras P, Valsami G, Effect of cyclodextrin complexation on the aqueous solubility and solubility/dose ratio of praziquantel. AAPS PharmSci Tech. 2009; 10: 1444-1451.

Martin Del Valle EM, Cyclodextrins and their uses: a review. Process Biochem. 2004; 39: 1033 - 1046.

Mura P, Faucci MT, Manderioli A, Bramanti G, Multicomponent systems of econazole with hydroxyacids and cyclodextrins, J Incl Phen, 2001; 39: 131-138.

Pouton CW, Lipid formulations for oral administration of drugs: non-emulsifying, self- emulsifying and 'self-microemulsifying' drug delivery systems, Eur J Pharm Sci, 2000; 11: S93-S98.
Piel G, Pirotte B, Delneuville I, Neven P, Llabres G, Delarge J, Dellatre L, Study of the influence of both cyclodextrins and L-lysine on the aqueous solubility of nimesulide; isolation and characterization of nimesulide-L-lysine-cyclodextrin complexes, J Pharm Sci, 1997; 86: 475 480 .

Renuka, Singh SK, Gulati M, Kaur I, Characterization of solid state forms of glipizide, Powder Technol, 2014; 264: 365-376.

Redenti E, Szente L, Szejtli J, Drug/cyclodextrin/hydroxy acid multicomponent systems. Properties and pharmaceutical applications, J Pharm Sci, 2000; 89: 1-8.

Redenti E, Szente L, J. Szejtli J, Cyclodextrin complexes of salts of acidic drugs.

Thermodynamic properties, structural features, and pharmaceutical applications, J Pharm Sci, 2001; 90: 979-986.

Rekharshy MY, Inoue Y, Detection of paramagnetic $\mathrm{pH}$ dependent Inclusion complexes, Chem Rev, 1998; 98: 1875-1896.

Ribeiro L, Loftsson T, Ferreira D, Veiga F, Investigation and physicochemical characterization of vinpocetine-sulfobutyl ether $\beta$ cyclodextrin binary and ternary complexes. Chem Pharm Bull, 2003; 51: 914-922.

Ribeiro LS, Ferreira DC, Veiga FJ. Physicochemical investigation of the effects of water- soluble polymers on vinpocetine complexation with beta-cyclodextrin and its sulfobutyl ether derivative in solution and solid state, Eur J Pharm Sci, 2003; 20: 253-266.

Ruan LP, Yu BY, Fu GM, Zhu DN, Improving the solubility of ampelopsin by solid dispersions and inclusion complexes, J Pharm Biomed Anal, 2005; 38: 457-464.

Singh SK, Srinivasan KK, Gowthamarajan K, Singare DS, Prakash D, Gaikwad NB,

Investigation of preparation parameters of nanosuspension by top-down media milling to improve the dissolution of poorly water-soluble glyburide, Eur J Pharm Biopharm, 2011; 78: 441-446.

Singh SK, Srinivasan KK, Gowthamarajan K, Prakash D, Gaikwad NB, Investigation of preparation parameters of solid dispersion and lyophilization technique in order to enhance the dissolution of poorly soluble glyburide, J Pharm Res, 2011; 4: 2718-2723.

Singh SK, Srinivasan KK, Singare DS, Gowthamarajan K, Prakash D, Formulation of ternary complexes of glyburide with hydroxypropyl- $\beta$-cyclodextrin and other solubilizing agents and their effect on release behavior of glyburide in aqueous and buffered media at different agitation speeds. Drug Dev Ind Pharm, 2012; 38: 1328-1336.

Szejli J. Cyclodextrin Technology. Dordrecht: Kluwer Academic Publishers (1998)

Tran PV, Bymaster FP, McNamara RK, Potter WZ. Dual monoamine modulation for improved treatment of major depressive disorder, J Clin Psychopharmacol, 2003; 23:78-86.

Uekama K, Hirayama F, Irie T, Cyclodextrin drug carrier systems, Chem Rev, 1998; 98: 2045-2076.

Vikmon M, Kolbe I, Szejtli J, Redenti E, Ventura P, Preparation and characterization of piroxicam alkali-salt $\gamma$-cyclodextrin complexes. Proceedings 9th Intern. Symp. Cyclodextrins. Dordrecht: Kluwer Academic Publishers (1999) pp 281-284.

Williams RO, Mahaguna V, Sriwongjanya M, Characterization of an inclusion complex of cholesterol and hydroxypropyl- $\beta$-cyclodextrin, Eur J Pharm Biopharm, 1998; 46: 355-360.

\section{How to cite this article:}

Pinakin Pandya, Narendra Kumar Pandey, Sachin Kumar Singh, Manish Kumar. Formulation and characterization of ternary complex of poorly soluble duloxetine hydrochloride. J App Pharm Sci, 2015; 5 (06): 088-096. 